\title{
Prevalence and detection of Stenotrophomonas maltophilia carrying metallo- $\beta$-lactamase blaL1 in Beijing, China
}

\author{
Zhan Yang ${ }^{1+}$, Wei Liu ${ }^{1+}$, Qian Cui ${ }^{1,2+}$, Wenkai $\mathrm{Niu}^{2+}{ }^{+}, \mathrm{Huan} \mathrm{Li}^{1}$, Xiangna Zhao ${ }^{1}$, Xiao Wei ${ }^{1}$, \\ Xuesong Wang ${ }^{1}$, Simo Huang ${ }^{1}$, Derong Dong ${ }^{1}$, Sijing $L^{3}{ }^{3}$, Changqing Bai ${ }^{2}$, Yan $\mathrm{Li}^{2}{ }^{*}, \mathrm{Liuyu}_{\mathrm{Huang}}{ }^{*}$ and $^{2}$ \\ Jing Yuan ${ }^{1}$ \\ 1 Institute of Disease Control and Prevention, Academy of Military Medical Sciences, Beijing, China \\ 2 Department of Respiratory Diseases, Affiliated Hospital of Academy of Military Medical Sciences, Beijing, China \\ ${ }^{3}$ Department of Respiration, The First Affiliated Hospital of Liaoning Medical University, Jinzhou, China
}

\section{Edited by:}

Faraj Barah, University of Kalamoon,

Syria

\section{Reviewed by:}

Adam Paul Roberts, University

College London, UK

Vijay Kumar, Doon PG College of

Agriculture Science Technology, India

\section{${ }^{*}$ Correspondence:}

Jing Yuan and Liuyu Huang, Institute of Disease Control and Prevention,

Academy of Military Medical

Sciences, No. 20 Dongda Street,

Fengtai District, Beijing 100071, China

e-mail: yuanjing6216@163.com;

huangliuyuly@163.com;

Yan Li, Department of Respiratory Diseases, Affiliated Hospital of

Academy of Military Medical

Sciences, No. 20 Dongda Street,

Fengtai District, Beijing 100071, China

e-mail: liyanmd@yahoo.com.cn

${ }^{\dagger}$ Zhan Yang, Wei Liu, Qian Cui, and Wenkai Niu have contributed equally to this work.
Intrinsic $\beta$-lactam resistance in Stenotrophomonas maltophilia is caused by bla $\mathrm{L}_{1}$ and/or blaL2, a kind of metallo- $\beta$-lactamase with a broad substrate spectrum including carbapenems. A rapid and sensitive molecular method for the detection of bla $\mathrm{L}_{\mathrm{L}}$ in clinical samples is needed to guide therapeutic treatment. In present study, we first described a loopmediated isothermal amplification (LAMP) method for the rapid detection of bla $\mathrm{L}_{\mathrm{L} 1}$ in clinical samples by using two methods including a chromogenic method using calcein/ $\mathrm{Mn}^{2+}$ complex and the real-time turbidity monitoring to assess the reaction. Then dissemination of L1-producing S. maltophilia was investigated from ICU patients in three top hospital in Beijing, China. The results showed that both methods detected the target DNA within 60 min under isothermal conditions $\left(65^{\circ} \mathrm{C}\right)$. The detection limit of LAMP was $3.79 \mathrm{pg} / \mu \mathrm{l}$ DNA, and its sensitivity 100-fold greater than that of conventional PCR. All 21 test strains except for $S$. maltophilia were negative for bla $\mathrm{L}_{1}$, indicative of the high-specificity of the primers for the bla $\mathrm{L} 1$. A total of $22 \mathrm{~L} 1$-positive isolates were identified for LAMPbased surveillance of bla 1 from $105 \mathrm{ICU}$ patients with clinically suspected multi-resistant infections. The sequences of these blaL1 genes were conservative with only a few sites mutated, and the strains had highly resistant to $\beta$-lactam antibiotics. The MLST recovered that 22 strains belonged to seven different $S$. maltophilia sequence types (STs). Furthermore, co-occurrence of bla $\mathrm{L} 1_{1}$ and bla $\mathrm{L2}$ genes were detected in all of isolates. Strikingly, S. maltophilia DCPS-01 was recovered to contain bla $a_{\mathrm{L} 1}, b / a_{\mathrm{L} 2}$, and bla ${ }_{\mathrm{NDM}-1}$ genes, possessing an ability to hydrolyse all $\beta$-lactams antibiotics. Our data showed the diversity types of $S$. maltophilia carrying bla $\mathrm{L}_{1}$ and co-occurrence of many resistant genes in the clinical strains signal an ongoing and fast evolution of $S$. maltophilia resulting from their wide spread in the respiratory infections, and therefore will be difficult to control.

Keywords: L1 metallo- $\beta$-lactamase, S. maltophilia, LAMP, rapid diagnosis, prevalence

\section{INTRODUCTION}

Stenotrophomonas maltophilia, commonly associated with respiratory infections in children and adults, is an emerging Gram-negative MDRO (multi-drug-resistant organism) of global significance (Brooke, 2012). Currently, the incidence of S. maltophilia nosocomial infection is increasing, particularly for the immunocompromised (cancer, cystic fibrosis, drug addicts, and AIDS patients), dialysis patients, recipients of organ transplants, in addition to the reported cases of community-acquired S. maltophilia. The low outer membrane permeability of S. maltophilia renders it inherently resistant to most antibiotics, whilst the production of group 2e $\beta$-lactamase (L2) and group $3 c \beta$-lactamase (L1) confers resistance to $\beta$-lactam containing antibiotics (Alonso and Martínez, 1997). The bla $a_{\mathrm{L} 1}$ existed on a 200-kb plasmid, encoding a broad-spectrum metallo- $\beta$-lactamase which hydrolyses carbapenems (Walsh etal., 1994; Avison et al., 2001), is usually produced at higher levels (induced) that hydrolyzes almost all known penicillins, cephalosporins, and carbapenems during $\beta$-lactam challenge. The ease of acquisition and spread of this antibiotic resistant gene of bla $a_{\mathrm{L} 1}$ in $S$. maltophilia emphasizes the need for antibiotic susceptibility testing of clinical isolates. At present, $b l a_{\mathrm{L} 1}$ has been identified in some clinical isolates of S. maltophilia with important drug resistance against carbapenems (Avison et al., 2001), so detection of bla $a_{\mathrm{L} 1}$ plays an important role to indicate the infection of $S$. maltophilia in the clinical work (Alonso and Martínez, 2000; AI-Jasser, 2006; Gould et al., 2006).

Recently, a number of molecular biology techniques have been used to detect different strains of S. maltophilia (Nakamura et al., 2010). PCR amplification of the 16 S rRNA gene was used to detect S. maltophilia in blood samples of patients who are undergoing chemotherapy for acute leukemia or myelodysplastic syndrome (Nakamura etal., 2010). However, PCR requires specialized high-cost instruments and consumables. In addition, Taq DNA polymerase in PCR assays can be inactivated by inhibitors present in crude biological samples but the large fragment of Bst DNA polymerase (the large fragment of Bst DNA polymerase is part 
of Bacillus stearothermophilus DNA polymerase, it has $5^{\prime}-3^{\prime}$ DNA polymerase activity) in loop-mediated isothermal amplification (LAMP) assays is more resistant to inhibitors present in crude biological samples (de Franchis et al., 1988; Kaneko et al., 2007). Thus, another rapid, simple and cost effective assay is needed to complement current PCR methods. The LAMP method which was developed in 2000 relies on auto-cycling strand displacement DNA synthesis which proceeds under isothermal conditions, typically within $60 \mathrm{~min}$, and in the presence of Bst DNA polymerase (Notomi et al., 2000; Song et al., 2005). In this study, we develop this new method to detect the $b l a_{\mathrm{L} 1}$ of $S$. maltophilia. The LAMP method has been shown to amplify target DNA with highspecificity, and it is used widely in the clinical detection of bacteria (Hara-Kudo et al., 2005; Ohtsuka et al., 2005), viruses (Okafuji et al., 2005), parasites (Chen et al., 2011; Kong et al., 2012), and for fetal sex identification (Hirayama et al., 2006).

Data on the prevalence of $b l a_{\mathrm{L} 1}$ in S. maltophilia from ICU of Chinese hospitals are lacking. The objective of the current study is to develop a rapid, simple assay for S. maltophilia and to further investigate the infection status and the species distribution of $b l a_{\mathrm{L} 1}$ in clinic. At first, we designed five primer sets which each set targets six or eight sequences on the bla $a_{\mathrm{L} 1}$. The specificity and sensitivity of the primers for $b l a_{L 1}$ was confirmed, and the LAMP method used for the detection of $b l a_{\mathrm{L} 1}$ in clinical samples. Then, basing on this LAMP assays, dissemination and molecular characterization of L1-producing S. maltophilia isolates was investigated at ICU patients in three top hospitals (the hospitals that have large scale and many patients) in Beijing, China.

\section{MATERIALS AND METHODS \\ BACTERIAL ISOLATES, IDENTIFICATION, MLST TYPING, AND ANTIMICROBIAL SUSCEPTIBILITY TESTING}

A total of 37 bacterial strains were used in this study to develop the LAMP assays, and their sources are listed in Table 1. S. maltophilia K279a carrying $b l_{\mathrm{L} 1}$ and $b l a_{\mathrm{L} 2}$ with the typical antimicrobial resistance properties was used as the positive control. The other species including common clinical infectious species and homologous species with $S$. maltophilia stored at our laboratory were used for estimating the sensitivity and specificity of the LAMP assay. 105 clinical nasopharyngeal swabs and sputum samples were collected from ICU hospitalized patients with clinically suspected multi-resistant infections in the 307 hospital, 302 hospital, and 301 hospital in China, and species identification was carried out using an automated system (Phoenix and BD systems) and matrix-assisted laser desorption ionization time-of-flight mass spectrometry (MALDI-TOF MS). $16 \mathrm{~S}$ rDNA and $b l a_{\mathrm{L} 1}$ were validated by PCR-based sequencing, and their sequence showed $100 \%$ (for $16 \mathrm{~S}$ rDNA) and $98-100 \%$ (for $b l a_{\mathrm{L} 1}$ ) identity with the sequences of previously reported genes, respectively. The allele number for each gene was assigned on the basis of the information in the MLST database ${ }^{1}$. A combination of the allelic sequences of the seven genes yielded the allelic profile. Antimicrobial susceptibility testing was performed by microbroth dilution according to the Clinical and Laboratory Standards Institute (CLSI, Clinical and Laboratory Standards Institute Performance standards for

\footnotetext{
${ }^{1}$ http://pubmlst.org/smaltophilia/
}

antimicrobial susceptibility testing; Twentieth informational supplement CLSI Document M100-S20, Wayne, PA, USA 2010.), and Etest strips (bioMérieux) for carbapenems. The carbapenemase activity of isolates was assessed by Etest MBLs.

The strains were screened for the presence of known MBL genes (bla $a_{\mathrm{VIM}}, b l a_{\mathrm{IMP}}, b l a_{\mathrm{SPM}-1}, b l a_{\mathrm{GIM}-1}, b l a_{\mathrm{SIM}-1}, b l a_{\mathrm{AIM}-1}$, and $b l a_{\mathrm{NDM}-1}$ ) by PCR with primers as reported previously (Patzer et al., 2009). The strains were also screened for the presence of other $\beta$-lactamase genes ( $b l a_{\mathrm{CTX}}, b l a_{\mathrm{CMY}}$, etc.; Poirel et al., 2007).

\section{ISOLATION OF GENOMIC DNA}

The 37 bacterial strains and the 105 clinical samples were cultured in brain heart infusion (BHI) broth at $37^{\circ} \mathrm{C}$ according to a standard protocol. Chelex ${ }^{\circledR} 100$ was used to extract total genomic DNA (including plasmid DNA) from $5 \mathrm{ml}$ overnight bacterial cultures. Briefly, $500 \mu \mathrm{l}$ bacterial suspension was centrifuged at $10,000 \times g$ for $2 \mathrm{~min}$ and the supernatant discarded. The pellet was resuspended in $500 \mu \mathrm{l}$ distilled water and $500 \mu \mathrm{l}$ Chelex DNA extraction buffer $(25 \mathrm{mM} \mathrm{NaOH}, 10 \mathrm{mM}$ Tris- $\mathrm{HCl}, 1 \%$ Triton X100, 1\% NP-40, 0.1 mM EDTA, 2\% Chelex-100) added. The cell suspension was heated in boiling water for $10 \mathrm{~min}$, held on ice for $5 \mathrm{~min}$, and centrifuged at $14,000 \times g$ for $2 \mathrm{~min}$. The extracted DNA was used as template in the LAMP and PCR reactions.

As for isolation of DNA from clinical sputum samples, DNA was extracted directly from $200 \mu \mathrm{l}$ clinical sputum samples with the TIANamp Genomic DNA Kit (TIANGEN Biotech Co., Ltd., Beijing, China). The DNA was purified with the SV GEL and PCR Clean-Up System (Promega Co., USA). The DNA concentration was detected using the Spectrophotometer ND-1000 (Thermo Fisher Scientific, Inc., USA).

\section{PRIMER DESIGN}

A total of $20 b l a_{L 1}$ in the NCBI GenBank database (GenBank: HQ822273.1; EF126060.1; EF126061.1; AM743169.1; AB294542.1; AJ251814.1; JF705927.1; JF705926.1; EF126051.1; EF126054.1; EF126053.1; EF601224.1; AB294547.1; AB294545.1; AJ291672.1; AF010282.1; AB194306.1; AJ289085.1; AJ289086.1; AB194305.1) were compared, then the sequences of conserved regions were chosen to design the primer sets. Primer Explorer V4 software ${ }^{2}$ was used to design the outer forward primer (F3), outer backward primer (B3), forward inner primer (FIP), backward inner primer (BIP) and backward loop primer (loop B), used to accelerate the amplification reaction. Mergers of bases are used to circumvent the mutational site (Table 2). The FIP and BIP primers were linked by a four thymidine spacer (TTTT). Conventional PCR was performed using primers labeled L1-23-F3 and L1-23-B3. The primers were synthesized by Sangon Biotech Co., Ltd. (Shanghai, China).

\section{LAMP REACTION}

A $25 \mu \mathrm{l}$ reaction volume was used for all LAMP reactions and contained the following components (final concentration): $20 \mathrm{mM}$ Tris- $\mathrm{HCl}$ ( $\mathrm{pH} 8.8$ ), $10 \mathrm{mM} \mathrm{KCl,} 10 \mathrm{mM}\left(\mathrm{NH}_{4}\right)_{2} \mathrm{SO}_{4}, 0.1 \%$ Tween 20, $0.8 \mathrm{M}$ betaine, $8 \mathrm{mM} \mathrm{MgSO}_{4}, 1.4 \mathrm{mM}$ each dNTP, and $8 \mathrm{U}$ Bst DNA polymerase. The amount of primer per reaction was $40 \mathrm{pmol}$

\footnotetext{
${ }^{2}$ http://primerexplorer.jp/e/
} 
Table 1 | Bacterial strains used in the current study.

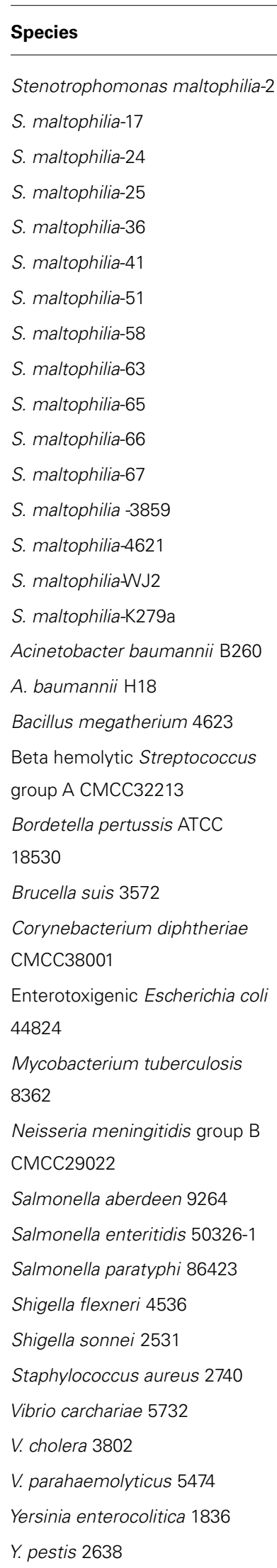

Source

\section{Clinical isolate \\ Clinical isolate \\ Clinical isolate \\ Clinical isolate \\ Clinical isolate \\ Clinical isolate \\ Clinical isolate \\ Clinical isolate \\ Clinical isolate \\ Clinical isolate \\ Clinical isolate \\ Clinical isolate \\ Clinical isolate \\ Clinical isolate \\ Clinical isolate}

Our microorganism center

Our microorganism center

Our microorganism center

Our microorganism center

Our microorganism center

Our microorganism center

Clinical isolate

Our microorganism center

Our microorganism center

Our microorganism center

Our microorganism center

Our microorganism center

Our microorganism center

Our microorganism center

Our microorganism center

Our microorganism center

Our microorganism center

Our microorganism center

Our microorganism center

Our microorganism center

Our microorganism center

Our microorganism center
FIP and BIP, 20 pmol LB, 5 pmol F3 and B3. The appropriate amount of DNA template was included in the reaction volume. The LAMP assay proceeded in a reaction tube (Eiken Chemical Co., Ltd., Tochigi, Japan) for $60 \mathrm{~min}$ at $65^{\circ} \mathrm{C}$.

\section{DETECTION OF LAMP PRODUCTS}

Two independent methods, based on either sample turbidity or fluorescence were used to detect LAMP products. Real-time changes in turbidity were monitored by measuring the optical density $\left(\lambda_{650} \mathrm{~nm}\right)$ at $6 \mathrm{~s}$ intervals, for each LAMP reaction in a Loopamp real-time turbidimeter (LA-320c; Eiken Chemical Co., Ltd.). The changes in turbidity arose from the presence of the amplification by-product $\mathrm{Mg}_{2} \mathrm{P}_{2} \mathrm{O}_{7}$ (a white precipitate).

The second method used direct visual inspection to assess color changes in the presence of the fluorescent metal ion indicator calcein/ $\mathrm{Mn}^{2+}$ complex. One microliter of calcein/ $\mathrm{Mn}^{2+}$ complex (Eiken Chemical Co., Ltd.) was added to $25 \mu$ l LAMP reaction volume prior to the commencement of the LAMP assay. On completion of the reaction a change in color from orange to green indicated a positive reaction, whilst no color change indicated a negative reaction. The color change was observed by the naked eye under natural light or under UV light at $365 \mathrm{~nm}$.

\section{PCR DETECTION}

A $25 \mu$ reaction volume was used for all PCR reactions and contained the following components: $12.5 \mu \mathrm{l}$ PCR Taq MasterMix (Tiangen Biotech Co., Ltd.), $9.5 \mu$ l double distilled water, $1 \mu \mathrm{M}$ L1-23F3 and L1-23B3 primers, and DNA template. The oligonucleotide primers used for cloning $b l a_{\mathrm{L} 1}$ are F: $5^{\prime}$-atgcgttctaccetgctcgccttcgcc- $3^{\prime}$ and R: $5^{\prime}$-tcagcgggccceggcc gtttccttggecag- $3^{\prime}$. The PCR was carried out as follows: initial PCR activation step, $94^{\circ} \mathrm{C}$ for $2 \mathrm{~min}$; amplification, 35 cycles of $94^{\circ} \mathrm{C}$ for $30 \mathrm{~s}, 59^{\circ} \mathrm{C}$ for $30 \mathrm{~s}$, and $72^{\circ} \mathrm{C}$ for $30 \mathrm{~s}$; final extension step, $72^{\circ} \mathrm{C}$ for $10 \mathrm{~min}$. The amplicons were purified using a PCR Purification Kit (TIANGEN Biotech Co., Ltd., Beijing, China) and sequenced by Beijing AuGCT DNASYN Biotechnology Co., Ltd. The sequences were compared with sequences in the GenBank database.

\section{RESULTS}

\section{THE OPTIMAL PRIMER SETS FOR LAMP ASSAY}

Five primer sets were detected in the same reaction condition using real-time turbidimeter and their turbidity curves were draw at $650 \mathrm{~nm}$ according to the amplified results. The optimal primer sets amplified the target sequence with the shortest time among them was chosen for further investigation (see Table 2).

\section{SENSITIVITY OF THE LAMP METHOD FOR bla 1 DETECTION}

The sensitivity of the LAMP method for detecting $b l a_{\mathrm{L} 1}$ was evaluated using genomic DNA extracted from S. maltophilia K279a (Wizard Genomic DNA purification Kit), serially diluted 10-fold from $379 \mathrm{ng} / \mu \mathrm{l}$ to $0.00379 \mathrm{pg} / \mu \mathrm{l}$. As shown in Figure 2A, the detection limit of the LAMP assay for $b l a_{L 1}$ was $3.790 \mathrm{pg} / \mu \mathrm{l}$. Visual inspection of the color change, post-LAMP assay, and in the presence of calcein $/ \mathrm{Mn}^{2+}$ complex confirmed reactions positive (green) and negative (orange) for $b l_{L 1}$ (Figure 2B). The results from the two detection methods were in agreement with sensitivity for $b l a_{\mathrm{L} 1}$. PCR reactions on the serially diluted DNA using primers 
Table 2 | Primers used for the amplification of bla $a_{\mathrm{L} 1}$.

\begin{tabular}{lll}
\hline Primer & Type & Sequence $\mathbf{( 5}^{\prime} \mathbf{- 3} \mathbf{)}$ \\
\hline L1-23F3 & Forward outer & CGGCATGCCACAGATGG \\
L1-23B3 & Backward outer & GCAGCACCGCCGTTTCT \\
L1-23FIP & Forward inner & TCAATCGCAGGTCCTGCGGTTTTCGGTCACCTGCTGGACAAC \\
L1-23BIP & Backward inner & CTY(C/T)AGCCATGCGCAY(T/C)GCS(C/G)GATTTTGCATTGGCCGCCACATG \\
L1-23LB & Loop backward & TCGCCGAGCTCAAGCGT \\
\hline
\end{tabular}
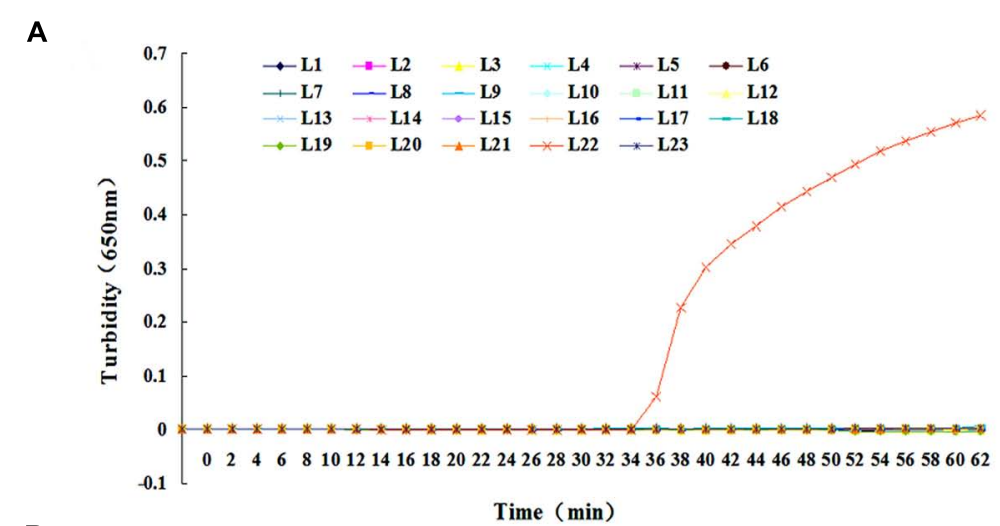

B
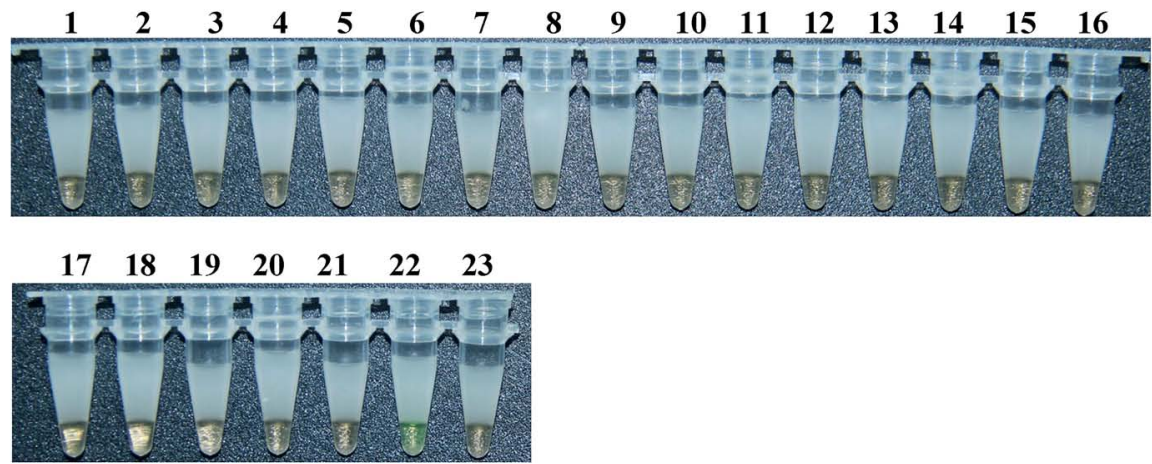

FIGURE 1 | Specificity of the LAMP method for bla detection. It has two parts, (A) is the graphic and (B) is the photography of microtubes. The reaction proceeded at $65^{\circ} \mathrm{C}$ for 65 min. Turbidity was monitored in the Loopamp real-time turbidimeter and the $O D_{(\lambda 650 \mathrm{~nm})}$ recorded at $6 \mathrm{~s}$ intervals. L1, Brucella suis 3572; L2, Bacillus megatherium 4623; L3, Vibrio carchariae 5732; L4, Acinetobacter baumannii B260; L5,

Corynebacterium diphtheriae CMCC38001; L6, Acinetobacter baumannii H18; L7, Mycobacterium tuberculosis 8362; L8, Shigella sonnei 2531;
L9, Shigella flexneri 4536; L10, Salmonella enteritidis 50326-1; L11, Yersinia enterocolitica 1836; L12, Vibrio parahaemolyticus 5474; L13, Salmonella paratyphi 86423; L14, Neisseria meningitidis group B CMCC29022; L15, Enterotoxigenic E. coli 44824; L16, Beta hemolytic Streptococcus group A CMCC32213; L17, Yersinia pestis 2638; L18, Salmonella aberdeen 9264; L19, Vibrio cholera 3802; L20, Staphylococcus aureus 2740; L21, Bordetella pertussis ATCC 18530; L22, positive control (S. maltophilia -K279a); L23, negative control (distilled water).
L1-23F3 and L1-23B3 were also conducted, and the detection limit for $b l a_{\mathrm{L} 1}$ was established as $379 \mathrm{pg} / \mu \mathrm{l}$ (Figure 2C).

\section{SPECIFICITY OF THE LAMP METHOD FOR bla ${ }_{L 1}$ DETECTION}

The specificity of the LAMP method for detecting $b l a_{\mathrm{L} 1}$ was evaluated using $S$. maltophilia $\mathrm{K} 279$ a with $b l a_{\mathrm{L} 1}$ as the positive control, distilled water as the negative control, and 21 strains without carrying $b l a_{\mathrm{L} 1}$ including common clinical infectious species and homologous species with S. maltophilia as test subjects. As shown in Figure 1A, turbidity increased only when S. maltophilia K279a with $b a_{\mathrm{L} 1}$ was used as template DNA in the LAMP assay. When distilled water and the 21 remaining bacterial species were used as template, no changes in turbidity were recorded. These results suggest that the primers had good specificity for $b l a_{\mathrm{L} 1}$. In addition, these results are consistent with those obtained using the fluorescent indicator calcein/ $\mathrm{Mn}^{2+}$ complex. Whereby, only the LAMP assay with S. maltophilia K279a with $b_{L 1} a_{L 1}$ recorded a color change from orange to green, indicative of a positive reaction (Figure 1B). Whilst, all test samples negative for $b l a_{L 1}$ and the negative control remained orange, indicative of a negative reaction. 
A

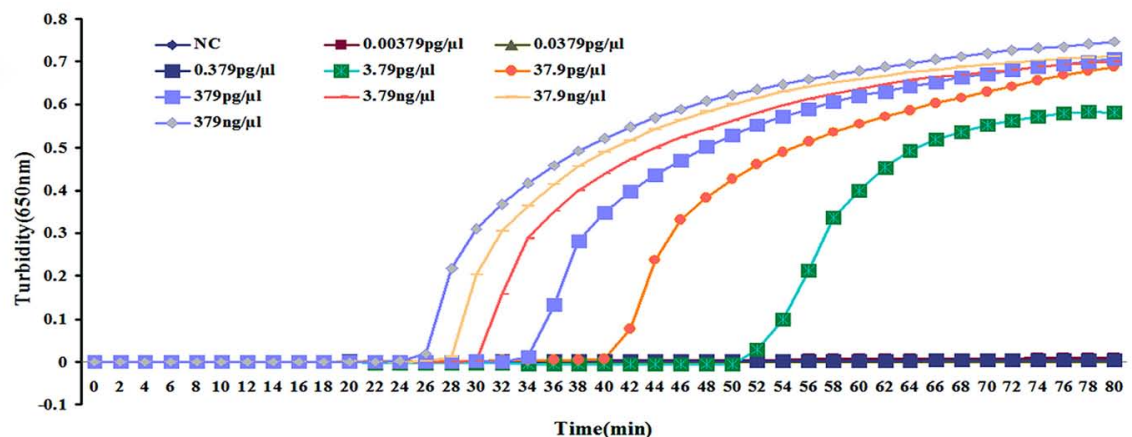

B

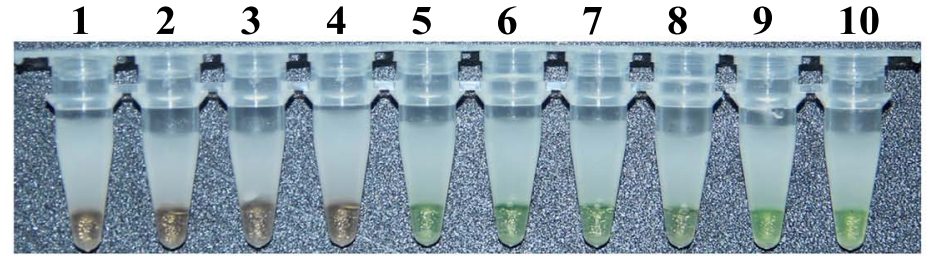

C

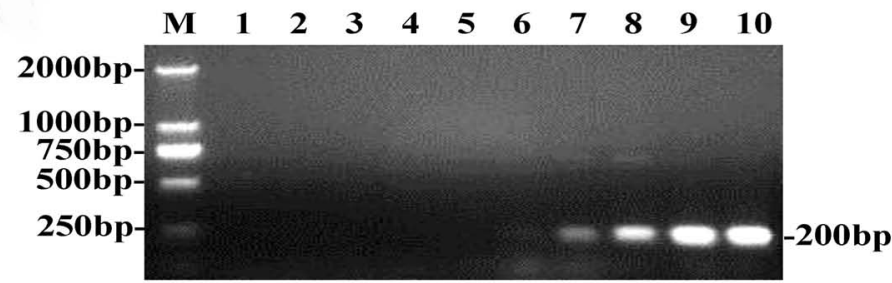

FIGURE 2 | Comparison of the sensitivities for $b a_{L 1}$ gene detection by LAMP and conventional PCR methods. Pure genomic DNA extracted from S. maltophilia-K279a was diluted tenfold $(379.0 \mathrm{ng} / \mu \mathrm{l}$ to $0.00379 \mathrm{pg} / \mu \mathrm{l})$ and the DNA assayed by LAMP (A,B) and PCR (C). (A) Turbidity was monitored using the Loopamp real-time turbidimeter and the OD recorded at $650 \mathrm{~nm}$, at
$6 \mathrm{~s}$ intervals. (B) Visual inspection of the color change, post-LAMP assay, and in the presence of calcein/ $\mathrm{Mn}^{2+}$ complex. (C) PCR products were analyzed by $2 \%$ agarose gel electrophoresis and stained with ethidium bromide. The DNA marker is D2000 DNA Marker (Tiangen Biotech Co., Ltd.) The size is about $179 \mathrm{bp}$.

\section{DISSEMINATION OF L1-PRODUCING $\boldsymbol{S}$. maltophilia IN CLINICAL}

A total of 105 clinical sputum samples and nasopharyngeal swabs were collected for LAMP-based surveillance of $b l a_{\mathrm{L} 1}$ from $105 \mathrm{ICU}$ patients with clinically suspected multi-resistant infections from the department of Respiratory Diseases in three top hospitals. Ten pairs of sputum samples and nasopharyngeal swabs from healthy people were collected as controls.

All clinical samples were analyzed by LAMP and PCR simultaneously. Of the 105 patients samples, 22 were confirmed to be infected with $S$. maltophilia with $b l a_{L 1}$ and 83 negative samples by the LAMP assay (Figure 3), whilst the PCR assay detected 13 positive samples, and 92 negative samples. Then 22 strains of S. maltophilia were isolated and identified from all of clinical sputum samples and swabs samples, which the positive samples were in accordence with those in LAMP assay. S. maltophilia with $b l a_{L 1}$ was positively identified $100 \%$ by LAMP and $86.7 \%$ by PCR, respectively. None of the samples from healthy people was tested as positive for $b l a_{L 1}$. Thus, the results showed the LAMP assays is more sensitive and the specific than PCR for diagnosis of $S$. maltophilia in clinical practice.

The sequence analysis of the $b l a_{\mathrm{L} 1}$ genes from $S$. maltophilia isolates confirmed conservation with the nucleotide sequences of reported genes or with only a few sites mutated. In the MLST analysis of S. maltophilia, the results of seven housekeeper genes recovered that 22 strains belonged to different sequence type (ST) including ST4, ST8, ST 25, ST 28, ST29, or ST31, respectively. To further characterize the 22 strains carrying $b l a_{L 1}$ genes, the susceptibility pattern was detected and clearly showed that all isolates had highly resistant to $\beta$-lactam antibiotics. The isolates also tested positive for MBLs in both the imipenem-EDTA double-disk synergy test (DDST) and modified Hodge test (MHT).

Furthermore, PCR screening of the isolates were performed for the known MBL genes including $b l a_{\mathrm{NDM}-1}$, bla $a_{\mathrm{VIM}}, b l a_{\mathrm{IMP}}$, $b l a_{\mathrm{SPM}-1}, b l a_{\mathrm{GIM}-1}, b l a_{\mathrm{SIM}-1}, b l a_{\mathrm{AIM}-1}$, and $b l a_{\mathrm{L} 2}$ (Patzer et al., 2009). PCR yielded products of 22 isolates with expected sizes for $b l a_{\mathrm{L} 1}$, and sequencing of these genes showed $100 \%$ identities with previously reported genes. It's interesting to note that the isolate named as S. maltophilia DCPS-01 contained L1 and L2 $\beta$-lactamase genes with a novel $b l a_{\mathrm{NDM}-1}$ which has attracted wide attention because of its superior resistance to all $\beta$-lactam antibiotics, which presented increased carbapenemase activity to all $\beta$-lactams (MIC $>128 \mu \mathrm{g} / \mathrm{mL}$ for imipenem and meropenem), aminoglycosides and quinolones, and was only susceptible to tigecycline and colistin.

Therefore, our data showed the diversity genotypic features of $S$. maltophilia carrying $b l a_{\mathrm{L} 1}$ indicated wide spread in the 


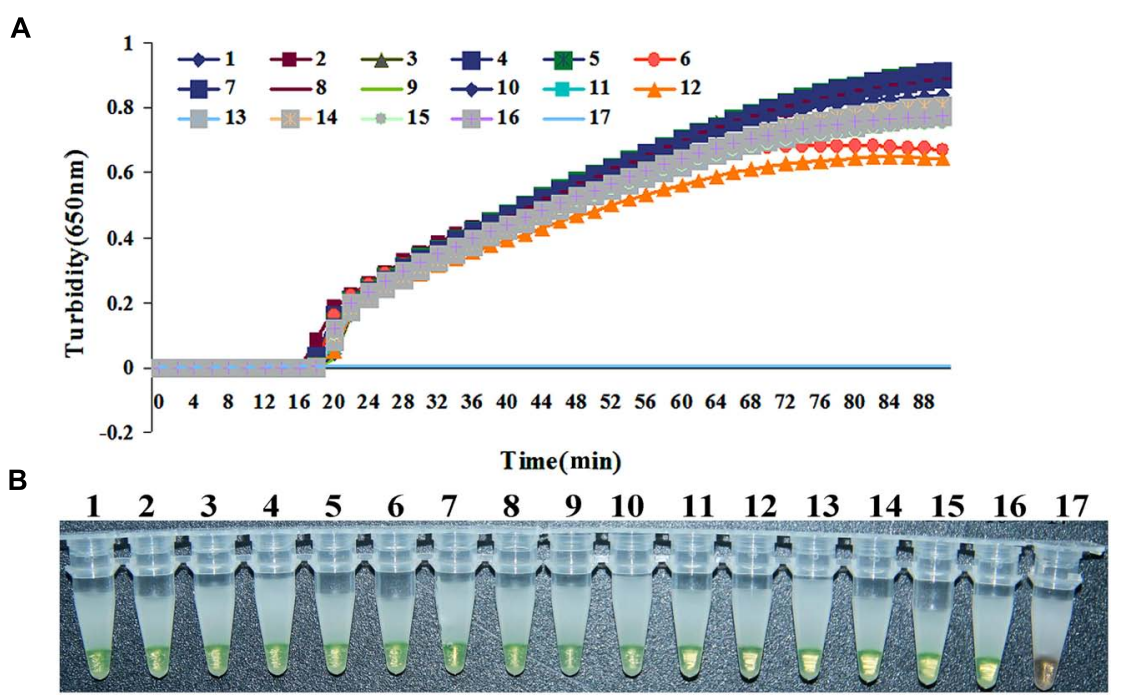

FIGURE 3 | Loop-mediated isothermal amplification results for $15 S$. maltophilia strains positive for bla $\mathrm{L}_{1}$ isolated from 15 clinical samples. (A) Turbidity was monitored using Loopamp, and the OD measured at $650 \mathrm{~nm}$ every $6 \mathrm{~s}$. (B) Visual inspection of calcein/ $\mathrm{Mn}^{2}+$ complex associated color changes post-LAMP assay. 1, S. maltophilia-2; 2, S. maltophilia-17; 3, S. maltophilia-24; 4, S. maltophilia-25; 5, S. maltophilia-36; 6, S. maltophilia-41; 7, S. maltophilia-51; 8, S. maltophilia-58; 9, S. maltophilia-63; 10, S. maltophilia-65; 11, S. maltophilia-66; 12, S. maltophilia-67; 13, S. maltophilia-3859; 14, S. maltophilia-4621; 15, S. maltophilia-WJ2; 16, positive control (S. maltophilia-K279a); 17, negative control (distilled water). respiratory infections. Importantly, the emergence of these powerful co-occurring resistance mechanisms described here provides warning that future therapeutic options may be seriously limited.

\section{DISCUSSION}

Stenotrophomonas maltophilia is a widespread environmental bacterium that has become a nosocomial pathogen of increasing importance. It is currently the third most common nosocomial non-fermenting bacteria, behind Pseudomonas aeruginosa and Acinetobacter baumannii, and is associxated with crude mortality rates ranging from 14 to $69 \%$ in patients with bacteraemias (Jang et al., 1992; Victor et al., 1994). Of the 1661 antibiotic resistant strains of S. maltophilia recovered from 14 hospitals across several regions of China during 2010, the majority (97.5\%) were isolated from patients. Approximately $68.3 \%$ of strains were isolated from patients $\geq 60$ years of age, whilst only $4.8 \%$ were from patients $<18$ years of age. Most (83.0\%) isolates were recovered from sputum and respiratory tract secretions (The data and information from CHINET: CHINET 2010 surveillance of antibiotic resistance in S. maltophilia in China). Within hospitals, the bacterium is most often found in water sources, and can be a contaminant of hospital equipment such as nebulizers and intravenous catheters. From these sources, the organism can infect patients, resulting in a wide spectrum of symptoms dependent upon the site of infection, though, most commonly, S. maltophilia causes bacteraemias or respiratory tract infections (Denton and Kerr, 1998). $\beta$-Lactam resistance is due to the expression of the $\beta$-lactamases $L 1$, which together hydrolyze the full range of $\beta$-lactam drugs, with the exception of monobactams (Walsh et al., 1994). It is therefore necessary to detect and monitor antibiotic resistance, persistence and spread of S. maltophilia within the community and in health care settings.
Loop-mediated isothermal amplification assays are generally less time and labor intensive compared with traditional methods of pathogen detection, in part because the amplification of the target gene is performed at a constant temperature, and the reaction times are usually less than an hour. To date, a method for detecting $S$. maltophilia based on LAMP assays has not been reported. In the current study, we designed primers specific for the metallo- $\beta$-lactamase $b l a_{\mathrm{L} 1}$ for use in a LAMP assay to detect S. maltophilia in clinical samples. Results from the specificity and sensitivity analyses demonstrated that the LAMP method detected genomic DNA at $3.79 \mathrm{pg} / \mu \mathrm{l}$, and was specific for the $\beta$-lactamase $b l a_{\mathrm{L} 1}$. In the specificity and sensitivity detection, we only use the bla $a_{\mathrm{L} 1}$ of S. maltophilia K279a as the target gene, although many other S. maltophilia strains do not have the same sequence of $b l a_{\mathrm{L} 1}$, the most conserve regions of $b l a_{\mathrm{L} 1}$ were chosed to design the decisive primers. In LAMP reaction, it is not true that all the primers should combine with the target sequence. The decisive primers are the FIP and BIP, if the FIP and BIP can combine with the target sequence, the reaction is certain to occur, well, of course, more novel experiments should be made to ensure this conclusion. Although the LAMP method has complex amplification principle, the assay is rapid, easy to operate, highly sensitive and specific, and proceeds under isothermal conditions. We believe this assay would be suitable for use in inspection and quarantine departments and in health care units to test for S. maltophilia, and we anticipate its routine use in hospital testing regimes, particularly for rapid clinical testing.

A drawback of the LAMP method is the relatively high falsepositive rates; a consequence of the assay's high sensitivity (Notomi et al., 2000). Strict spatial separation of reagent preparation from the testing area is necessary to avoid contamination. In the current study, a sealing agent was applied to the reaction tube once the 
reaction mixture had been prepared, and its presence is useful in preventing contamination.

In conclusion, we designed a detection method based on LAMP for the specific, sensitive, rapid, and effective detection of the metallo- $\beta$-lactamase $b l_{\mathrm{L} 1}$ of $S$. maltophilia. We believe this technique would greatly benefit hospitals and health units, and we anticipate that LAMP will become the gold standard for the rapid detection of pathogens in clinical samples. At the same time, this report provides new insights into the mechanisms of drug resistance and warning that future therapeutic options may be seriously limited.

\section{AUTHOR CONTRIBUTIONS}

Jing Yuan helped conceive project and designed experiments. Zhan Yang, Wei Liu, and Qian Cui performed and wrote the manuscript. Huan Li, Xiangna Zhao, Xiao Wei, Xuesong Wang, Wenkai Niu, Changqing Bai, Yan Li, and Liuyu Huang designed and executed experiments. Simo Huang, Derong Dong, and Sijing Lu helped to edit the manuscript.

\section{ACKNOWLEDGMENTS}

We are indebted to the Department of Respiratory Diseases, Affiliated Hospital of Academy of Military Medical Science for kindly providing S. maltophilia and helpful information. We are grateful to LI Fengjing and XIAO Shengli from Beijing Lanpu Bio-tech Co., Ltd. for providing technical assistance and for participating in helpful discussions. This work was supported by Mega-projects of Science and Technology Research of China Grant 2011ZX10004001 and 2013ZX10004-203, National Natural Science Foundation of China Grant 31370093 and 81201320, and National High Technology Research and Development Program of China 863 Program Grant SS2014AA022210.

\section{REFERENCES}

AI-Jasser, A. M. (2006). Stenotrophomonas maltophilia resistant to trimethoprim sulfamethoxazole: an increasing problem. Ann. Clin. Microbiol. Antimicrob. 5, 23. doi: 10.1186/1476-0711-5-23

Alonso, A., and Martínez, J. L. (1997). Multiple antibiotic resistance in Stenotrophomonas maltophilia. Antimicrob. Agents Chemother. 41, 1140-1142.

Alonso, A., and Martínez, J. L. (2000). Cloning and characterization of SmeDEF, a novel multidrug effux pump from Stenotrophomonas maltophilia. Antimicrob. Agents Chemother. 44, 3079-3086. doi: 10.1128/AAC.44.11.30793086.2000

Avison, M. B., Higgins, C. S., von Heldreich, C. J., Bennett, P. M., and Walsh, T. R. (2001). Plasmid location and molecular heterogeneity of the L1 and L2 $\beta$ lactamase genes of Stenotrophomonas maltophilia. Antimicrob. Agents Chemother. 45, 413-419. doi: 10.1128/AAC.45.2.413-419.2001

Brooke, J. S. (2012). Stenotrophomonas maltophilia: an emerging global opportunistic pathogen. Clin. Microbiol. Rev. 25, 2-41. doi: 10.1128/CMR.00019-11

Chen, R., Tong, Q., Zhang, Y., Lou, D., Kong, Q., Lv, S., et al. (2011). Loop-mediated isothermal amplification: rapid detection of Angiostrongylus cantonensis infection in Pomacea canaliculata. Parasit. Vectors 4, 204. doi: 10.1186/1756-3305-4-204

de Franchis, R., Cross, N. C., Foulkes, N. S., and Cox, T. M. (1988). A potent inhibitor of Taq polymerase copurifies with human genomic DNA. Nucleic Acids Res. 16, 10355. doi: 10.1093/nar/16.21.10355

Denton, M., and Kerr, K. G. (1998). Microbiological and clinical aspects of infection associated with Stenotrophomonas maltophilia. Clin. Microbiol. Rev. 11, $57-80$.

Gould, V. C., Okazaki, A., and Avison, M. B. (2006). Beta-lactam resistance and beta-lactamase expression in clinical Stenotrophomonas maltophilia isolates having defined phylogenetic relationships. J. Antimicrob. Chemother. 57, 199-203. doi: $10.1093 / \mathrm{jac} / \mathrm{dki} 453$
Hara-Kudo, Y., Yoshino, M., Kojima, T., and Ikedo, M. (2005). Loop-mediated isothermal amplification for the rapid detection of Salmonella. FEMS Microbiol. Lett. 253, 155-161. doi: 10.1016/j.femsle.2005.09.032

Hirayama, H., Kageyama, S., Takahashi, Y., Moriyasu, S., Sawai, K., Onoe, S., et al. (2006). Rapid sexing of water buffalo (Bubalus bubalis) embryos using loop-mediated isothermal amplification. Theriogenology 66, 1249-1256. doi: 10.1016/j.theriogenology.2006.03.036

Jang, T. N., Wang, F. D., Wang, L. S., Liu, C. Y., and Liu, I. M. (1992). Xanthomonas maltophilia bacteremia: an analysis of 32 cases. J. Formos. Med. Assoc. 91, 11701176. doi: 10.1093/jac/dkn194

Kaneko, H., Kawana, T., Fukushima, E., and Suzutani, T. (2007). Tolerance of loopmediated isothermal amplification to a culture medium and biological substances. J. Biochem. Biophys. Methods 70, 499-501. doi: 10.1016/j.jbbm. 2006.08.008

Kong, Q. M., Lu, S. H., Tong, Q. B., Lou, D., Chen, R., Zheng, B., et al. (2012). Loop-mediated isothermal amplification (LAMP): early detection of Toxoplasma gondii infection in mice. Parasit. Vectors 5, 2. doi: 10.1186/1756-3305-5-2

Nakamura, A., Sugimoto, Y., Ohishi, K., Sugawara, Y., Fujieda, A., Monma, F., et al. (2010). Diagnostic value of PCR analysis of bacteria and fungi from blood in empiric-therapy-resistant febrile neutropenia. J. Clin. Microbiol. 48, 2030-2036. doi: 10.1128/JCM.01700-09

Notomi, T., Okayama, H., Masubuchi, H., Yonekawa, T., Watanabe, K., Amino, N., et al. (2000). Loop-mediated isothermal amplification of DNA. Nucleic Acids Res. 28:E63. doi: 10.1093/nar/28.12.e63

Ohtsuka, K., Yanagawa, K., Takatori, K., and Hara-Kudo, Y. (2005). Detection of Salmonella enterica naturally contaminated liquid eggs by loop-mediated isothermal amplification, and characterization of Salmonella isolates. Appl. Environ. Microbiol. 71, 6730-6735. doi: 10.1128/AEM.71.11.6730-6735.2005

Okafuji, T., Yoshida, N., Fujino, M., Motegi, Y., Ihara, T., Ota, Y., et al. (2005). Rapid diagnostic method for detection of mumps virus genome by loopmediated isothermal amplification. J. Clin. Microbiol. 43, 1625-1631. doi: 10.1128/JCM.43.4.1625-1631. 2005

Patzer, J. A., Walsh, T. R., Weeks, J., Dzierzanowska, D., and Toleman, M. A. (2009). Emergence and persistence of integron structures harbouring VIM genes in the Children's Memorial Health Institute, Warsaw, Poland, 1998-2006. J. Antimicrob. Chemother. 63, 269-273. doi: 10.1093/jac/dkn512

Poirel, L., Pitout, J. D., and Nordmann, P. (2007). Carbapenemases: molecular diversity and clinical consequences. Future Microbiol. 2, 501-512. doi: 10.2217/17460913. 2.5.501

Song, T., Toma, C., Nakasone, N., and Iwanaga, M. (2005). Sensitive and rapid detection of Shigella and enteroinvasive Escherichia coli by a loop-mediated isothermal amplification method. FEMS Microbiol. Lett. 243, 259-263. doi: 10.1016/j.femsle.2004.12.014

Victor, M. A., Arpi, M., Bruun, B., Jønsson, V., and Hansen, M. M. (1994). Xanthomonas maltophilia bacteremia in immunocompromised hematological patients. Scand. J. Infect. Dis. 26, 163-170. doi: 10.3109/00365549409011780

Walsh, T. R., Hall, L., Assinder, S. J., Nichols, W. W., Cartwright, S. J., MacGowan, A. P., etal. (1994). Sequence analysis of the L1 metallo- $\beta$-lactamase from Xanthomonas maltophilia. Biochim. Biophys. Acta 1218, 199-201. doi: 10.1016/0167-4781(94) 90011-6

Conflict of Interest Statement: The authors declare that the research was conducted in the absence of any commercial or financial relationships that could be construed as a potential conflict of interest.

Received: 29 August 2014; paper pending published: 02 October 2014; accepted: 22 November 2014; published online: 09 December 2014.

Citation: Yang Z, Liu W, Cui Q, Niu W, Li H, Zhao X, Wei X, Wang X, Huang S, Dong D, Lu S, Bai C, Li Y, Huang L and Yuan J (2014) Prevalence and detection of Stenotrophomonas maltophilia carrying metallo- $\beta$-lactamase blaL1 in Beijing, China. Front. Microbiol. 5:692. doi: 10.3389/fmicb.2014.00692

This article was submitted to Antimicrobials, Resistance and Chemotherapy, a section of the journal Frontiers in Microbiology.

Copyright (C) 2014 Yang, Liu, Cui, Niu, Li, Zhao, Wei, Wang, Huang, Dong, Lu, Bai, Li, Huang and Yuan. This is an open-access article distributed under the terms of the Creative Commons Attribution License (CC BY). The use, distribution or reproduction in other forums is permitted, provided the original author(s) or licensor are credited and that the original publication in this journal is cited, in accordance with accepted academic practice. No use, distribution or reproduction is permitted which does not comply with these terms. 